dilatation and increased temperature and can often be mistaken for an embolic or thrombotic event to the contralateral limb. ${ }^{4}$ These patients are young, and hypotension usually does not limit or delay ambulation. However, when mobilized, these patients develop postural hypotension and require 500-1000 $\mathrm{mL}$ of $i v$ fluid in addition to the postoperative maintenance $i v$ fluids. In patients with extensive dissection, the hemodynamic instability lasts for one to two weeks postoperatively, after which time the signs of unilateral sympathectomy disappear or become minimal due to compensatory mechanisms.

Mariana Mogos MD

Peter Roffey MD

Maged Mikhail MD

Duraiyah Thangathurai MD

Los Angeles, California

References

1 Black DR, Kassinove AS, Mikhail M, Stein J, Thangathurai $D$. Lower extremity temperature disparity after retroperitoneal dissection (Letter). Can J Anesth 1999; 46: 808.

2 Thangathurai D, Mikhail M, Fishman D. Inadequate analgesia with lumbar epidural following retroperitoneal dissection. Can J Anaesth 1990; 37: 597.

3 Donobue JP, Rowland RG. Complications of retroperitoneal lymph node dissection. J Urol 1981; 123 : 338-40.

4 Skinner DG, Melamud A, Lieskovsky G Complications of thoracoabdominal retroperitoneal lymph node dissection. J Urol 1982; 127: 1107-10.

\section{Do preoperative anxiety and depression affect quality of recovery and length of stay after hip or knee arthroplasty?}

To the Editor:

Early detection of patients likely to suffer poor postoperative quality of recovery (QOR) and prolonged length of stay (LOS) in hospital enables prompt mobilization of support services, efficient discharge, and cost reduction. Previous studies designate advanced age and female gender as predictive of poor QOR and prolonged $\operatorname{LOS}^{2,3}$ after major orthopedic surgery. Given the prevalence and morbidity of anxiety and depression in the elderly, we considered the effect of these disorders on QOR and LOS after hip or knee arthroplasty.

We examined 38 random adult patients undergoing elective hip or knee arthroplasty. Preoperatively, patients completed the Hospital Anxiety and Depression Scale ${ }^{4}$ which screens for anxiety and depression and provides a measure of severity for each disorder. On the fourth postoperative day, patients completed the QOR Score ${ }^{1}$ which yields a measure of postoperative health status including emotional state, physical independence, and pain. Bivariate correlations between preoperative variables (anxiety; depression) and postoperative outcomes (QOR; LOS) were evaluated with two-tailed tests of significance. Spearman correlation coefficients $(r)$ were calculated for all patients in aggregate and for subgroups based on age, gender, and type of surgery.

Between increased anxiety and reduced QOR, we demonstrated a significant correlation for all patients in aggregate $(r=-0.505 ; P=0.001)$, and a significant correlation for each subgroup of patients analyzed, except hip arthroplasty. For all patients in aggregate, we found no correlation between anxiety and LOS, depression and QOR, or depression and LOS.

Our preliminary results suggest an association between preoperative anxiety and poor QOR after hip or knee arthroplasty.

Richard Brull MD, Colin J.L. McCartney MBCHB FFARCSI FRCA

Vincent W.S. Chan MD FRCPC

Toronto, Ontario

References

1 Myles PS, Hunt JO, Nightingale CE, et al. Development and psychometric testing of a quality of recovery score after general anesthesia and surgery in adults. Anesth Analg 1999; 88: 83-90.

2 Rissanen P, Aro S, Paavolainen P. Hospital- and patient-related characteristics determining length of hospital stay for hip and knee replacements. Int J Technol Assess Health Care 1996; 12: 325-35.

3 Collins TC, Daley J, Henderson WH, Khuri SF. Risk factors for prolonged length of stay after major elective surgery. Ann Surg 1999; 230: 251-9.

4 Zigmond AS, Snaith RP. The hospital anxiety and depression scale. Acta Psychiatr Scand 1983; 67: 361-70.

\section{Radial artery cannulation in edema- tous patients}

To the Editor:

Cannulation of peripheral arteries is a useful procedure for monitoring of arterial pressure and analysis of 
blood gases. In edematous patients cannulation of peripheral arteries and veins becomes difficult, owing to the presence of excessive perivascular interstitial fluid. Thus, arterial pulsations become feeble and at times impalpable. This leads to repeated attempts at cannulation and even failure.

A 26-yr-male patient with myeloid leukemia in accelerated phase with massive splenomegaly and anasarca was admitted for splenectomy. Following intubation, right radial artery cannulation was attempted with a $22 \mathrm{G}$ cannula. It was difficult to palpate the radial artery, which was punctured on the third attempt but could not be cannulated. Thereafter, pressure was applied over the puncture site for two minutes to prevent hematoma formation. Once the pressure was released, there was a depression at the site due to redistribution of edema fluid and the radial artery was easily palpated. Subsequently, the artery could be punctured and cannulated easily on the second attempt.

In patients with pitting edema there is exudation of fluid in the interstitial space. Neonates and more so preterms have relatively more total body fluid (interstitial fluid). ${ }^{1}$ Displacement of perivascular interstitial fluid by pressure over the peripheral artery makes the course of the artery visible, rendering cannulation under direct vision easy in pediatric patients. ${ }^{2}$ Although the radial artery lies deep to the deep fascia, the overlying interstitial fluid can be displaced by applying pressure, making arterial palpation easy and facilitating cannulation.

\section{A. Agarwal MD \\ D. Sahu MD \\ N. Bose MD \\ Lucknow, India}

\section{References}

1 Stoelting RK, Dierdorf SF, McCammon RL. Water and Electrolyte disturbances. In: Stoelting RK, Dierdorf SF, McCammon RL (Eds.). Anesthesia and Co-existing Disease, $2^{\text {nd }}$ ed. New York: Churchill Livingstone Inc., 1988: 445-71.

2 Raichur $D V$. Radial artery cannulation in Neonates: a new method. Indian Journal of Pediatrics 2000; 67: 843.

\section{Airway loss during tracheostomy}

To the Editor:

We read with interest the case report by McGuire et al. ${ }^{1}$ We agree that the jet ventilation/airway exchange catheter employed during endotracheal tube exchange in patients with a difficult airway, ${ }^{2}$ appears useful during elective tracheostomy. We describe a rapid method of re-establishing the airway in patients who suffered emergency airway loss during/after tracheostomy.

In the first patient, who had just undergone a reconstructive procedure over the face and neck, the tracheostomy tube became dislodged during transport. Attempted reinsertion failed due to severe neck edema. Two patients with neck tumours suffered airway loss during tracheostomy for prolonged intubation. Re-insertion of the tracheostomy tube was not possible and they could not be ventilated.

In all three cases, we successfully secured the airway simply with the use of a finger! The index or middle finger was inserted through the tracheostomy incision, the fingertip palpating through layers to locate the tracheal incision. Feeling the tracheal rings confirmed passage into the trachea. Alternatively, the cervical vertebral bodies may be located first, traced to the esophagus and trachea, and then along the trachea to locate the incision. Obviously, once the finger is in the trachea, there is no room for a tracheostomy or endotracheal tube. Therefore, a gum elastic bougie (Rüsch, Willy Riisch AG, Kernen, Germany) is guided into the trachea alongside the finger and placement confirmed by palpation. An endotracheal tube is then threaded over the bougie. The time taken to regain the airway was between 20 to $40 \mathrm{sec}$. Effective ventilation was re-established in all three patients and none suffered any neurological sequelae.

When faced with difficult airways, sometimes a simple manoeuvre is all that is required. The anesthesiologist fingers, sensitive and readily available, should not be forgotten, especially when more sophisticated equipment is not on hand.

Ka-Shun Cheng MD

Taipei

Ju-Mei Ng MMED

Singapore

\section{References}

1 McGuire G, El-Beheiry H, Brown D Loss of the airway during tracheostomy: rescue oxygenation and re- establishment of the airway. Can J Anesth 2001; 48: 697-700.

2 Cooper RM. Extubation and changing endotracheal tubes. In: Benumof JL (Ed.). Airway Management. Principles and Practice. Mosby, 1995: 864-85.

REPLY:

We thank Cheng and $\mathrm{Ng}$ for their comments. Our case report dealt with a different situation than 